\title{
Durchlauchtigster Fürst! Gnädigster Herr Staats-Kanzler!
}

Euer Durchlaucht hatten die Gnade; mir meine unterthänigste Bitte, meine im Verlage der Flittnerschen Buchhandlung in Berlin herausgegebene Bibliotheca juris civilis Iustinianei Höchstdenenselben unterthänigst zueignen zu dürfen, gnädig zu gewähren. Diese gnädige Erlaubnifs schmückt diesen litterarischen Versuch eines fast 7ojahrigen Greises mit der ehrenvollsten Zierde, indem sie ihm gestattet, diesem Werke den Namen eines Fürsten in dieser ZueignungsSchrift vorzusetzen, welchen der KöniglichPrenssische Herrscher-Staat sowohl, als das ganze Teutsche Vaterland, mit Recht zu den allerkenntnifsreichsten und einsichtsvollsten Gliedern des erhabenen Fürsten. Standes 
zählet. Ich erdreiste mich nur noch, die Versicherung der unbegrenzten und tiefen Ehrerbietung hinzuzufügen, mit welcher ich verharre

\section{Euer Durchlaucht, meines gnädigsten Herrn Staats- Kanzlers}

unterthanigster und gehorsamster

Friedrich.Wilhelm Freyherr von Ulmenstein 